\title{
Carotid intima-media thickness in patients with subclinical hypothyroidism: A prospective controlled study
}

\author{
Anally Soto-García ${ }^{1}$, Guillermo Elizondo-Riojas ${ }^{1}$, Rene Rodriguez-Gutiérrez ${ }^{1}$, Leonardo \\ Mancillas-Adame ${ }^{1}$, and Jose Gerardo Gonzalez-Gonzalez ${ }^{1}$ \\ ${ }^{1}$ Hospital Universitario Dr José Eleuterio González
}

December 19, 2020

\begin{abstract}
Background: The association between subclinical hypothyroidism ( $\mathrm{SCH}$ ) and cardiovascular risk, particularly with a TSH $<10 \mu \mathrm{IU} / \mathrm{ml}$, remains controversial. The objective of our study was to assess the association between SCH and cardiovascular risk through carotid intima-media thickness, and alternatively, to evaluate its change after treatment with levothyroxine. Methods: A total of 54 individuals were included in the study, 18 with SCH, 18 with overt hypothyroidism (OH), and 18 healthy controls (HC). The carotid intima-media thickness was measured in each group. In SCH, follow-up was performed at three and six months after the start of levothyroxine. Results: The mean age of the total population at baseline was 35.8 years. The median TSH in SCH was $6.15 \mu \mathrm{IU} / \mathrm{ml}$. The carotid intima-media thickness was greater in SCH in comparison to the HC group (Right common carotid artery [RCCA, mm]: $0.486 \pm 0.106$ and $0.413 \pm 0.075$ in SCH and HC, respectively, p=0.01. Left common carotid artery [LCCA, mm]: $0.511 \pm 0.144$ and $0.427 \pm 0.090$ in $\mathrm{SCH}$ and $\mathrm{HC}$, respectively, p=0.03). In patients with SCH, there was a decrease in the carotid intima-media thickness after treatment with levothyroxine (RCCA and LCCA p $<0.05$ at 3 and 6 months). Conclusions: There is an association between an increase in the carotid intima-media thickness in patients with $\mathrm{SCH}$ in comparison to $\mathrm{HC}$, even with a $\mathrm{TSH}<10 \mu \mathrm{IU} / \mathrm{ml}$. The increase reversed with levothyroxine therapy. Its association with important cardiovascular outcomes remains uncertain and should be evaluated in future studies.
\end{abstract}

\section{Carotid intima-media thickness in patients with subclinical hypothyroidism: A prospective controlled study}

\section{Running title: Intima-media in subclinical hypothyroidism}

Anally Jamile Soto-García ${ }^{1}$, Guillermo Elizondo-Riojas ${ }^{2}$, Rene Rodriguez-Gutiérrez ${ }^{1,3,4,5}$, Leonardo Guadalupe Mancillas-Adame ${ }^{1,3}$, Jose Gerardo González-González ${ }^{1,5}$

${ }^{1}$ Universidad Autonoma de Nuevo Leon, Facultad de Medicina y Hospital Universitario "Dr. Jose Eleuterio Gonzalez", Endocrinology Division, Av. Madero y Gonzalitos s/n, Colonia Mitras Centro, Monterrey, Nuevo León, Mexico 64460

${ }^{2}$ Universidad Autonoma de Nuevo Leon, Facultad de Medicina y Hospital Universitario "Dr. Jose Eleuterio Gonzalez", Radiology and Image Department, Av. Madero y Gonzalitos s/n, Colonia Mitras Centro, Monterrey, Nuevo Leon, Mexico 64460

${ }^{3}$ Universidad Autonoma de Nuevo Leon, Plataforma INVEST Medicina UANL-KER Unit Mayo Clinic (KER Unit Mexico), Av. Madero y Gonzalitos s/n, Colonia Mitras Centro, Monterrey, Nuevo Leon, Mexico 64460

${ }^{4}$ Knowledge and Evaluation Research Unit in Endocrinology, Mayo Clinic, Plummer Building, Third Floor, 200 First St. SW, Rochester, MN 55905 
${ }^{5}$ Universidad Autonoma de Nuevo Leon, Facultad de Medicina y Hospital Universitario "Dr. Jose Eleuterio Gonzalez", Research Unit, Av. Madero y Gonzalitos s/n, Colonia Mitras Centro, Monterrey, Nuevo Leon, Mexico 64460

\section{Corresponding Author}

José Gerardo González-González MD, PhD.

Servicio de Endocrinología

Facultad de Medicina y Hospital Universitario "Dr. José E. González"

Av. Francisco I. Madero y Av. Gonzalitos s/n, Colonia Mitras Centro, Monterrey, Nuevo Leon, Mexico C.P. 64460

Phone number: +528183483220

ORCID: 0000-0002-6609-9483

jgerardo@meduanl.com.

Acknowledgments

None.

\section{ABSTRACT}

Background: The association between subclinical hypothyroidism $(\mathrm{SCH})$ and cardiovascular risk, particularly with a TSH $<10 \mu \mathrm{IU} / \mathrm{ml}$, remains controversial. The objective of our study was to assess the association between SCH and cardiovascular risk through carotid intima-media thickness, and alternatively, to evaluate its change after treatment with levothyroxine.

Methods: A total of 54 individuals were included in the study, 18 with SCH, 18 with overt hypothyroidism $(\mathrm{OH})$, and 18 healthy controls $(\mathrm{HC})$. The carotid intima-media thickness was measured in each group. In $\mathrm{SCH}$, follow-up was performed at three and six months after the start of levothyroxine.

Results: The mean age of the total population at baseline was 35.8 years. The median TSH in SCH was $6.15 \mu \mathrm{IU} / \mathrm{ml}$. The carotid intima-media thickness was greater in SCH in comparison to the HC group (Right common carotid artery [RCCA, mm]: $0.486 \pm 0.106$ and $0.413 \pm 0.075$ in SCH and HC, respectively, $\mathrm{p}=0.01$. Left common carotid artery [LCCA, mm]: $0.511 \pm 0.144$ and $0.427 \pm 0.090$ in SCH and HC, respectively, $\mathrm{p}=0.03)$. In patients with $\mathrm{SCH}$, there was a decrease in the carotid intima-media thickness after treatment with levothyroxine (RCCA and LCCA $\mathrm{p}<0.05$ at 3 and 6 months).

Conclusions: There is an association between an increase in the carotid intima-media thickness in patients with SCH in comparison to $\mathrm{HC}$, even with a TSH $<10 \mu \mathrm{IU} / \mathrm{ml}$. The increase reversed with levothyroxine therapy. Its association with important cardiovascular outcomes remains uncertain and should be evaluated in future studies.

Keywords : Mild subclinical hypothyroidism, cardiovascular risk, carotid intima-media thickness.

\section{What's already known about this topic?}

Overt hypothyroidism has been associated with increased fatal and nonfatal cardiovascular disease. However, studies of the association of subclinical hypothyroidism and cardiovascular risk have shown controversial results, particularly in mild subclinical hypothyroidism (thyrotropin $[\mathrm{TSH}]<10 \mu \mathrm{IU} / \mathrm{ml}$ ).

In terms of cardiovascular risk prediction, carotid intima-media thickness is a marker of atherosclerosis well studied.

What does this article add? 
There is a significant increase in the carotid intima-media thickness in patients with subclinical hypothyroidism when compared to healthy controls, even in mild subclinical hypothyroidism. In addition, carotid intima-media thickness showed a significant reduction following treatment with levothyroxine.

The current study suggests that there is an increase in cardiovascular risk in subclinical hypothyroidism with TSH less or greater than $10 \mu \mathrm{IU} / \mathrm{ml}$, and its treatment could potentially reduce this risk.

\section{Introduction}

The worldwide prevalence of overt hypothyroidism $(\mathrm{OH})$ and subclinical hypothyroidism $(\mathrm{SCH})$ ranges from $0.2-5 \%^{1,2}$ and $4.9-10^{1,3}$ respectively. $\mathrm{OH}$ and $\mathrm{SCH}$ have been associated with dyslipidemia ${ }^{4}$, fatty liver disease, ${ }^{5,6}$ and decreased adrenal reserve. ${ }^{7} \mathrm{OH}$ has also been associated with increased fatal and nonfatal cardiovascular disease. ${ }^{8,9}$ However, studies of the association of SCH and cardiovascular risk have shown controversial results, particularly in mild SCH (thyrotropin $[\mathrm{TSH}]<10 \mu \mathrm{IU} / \mathrm{ml}$ ). ${ }^{10}$ Some population databases have found an increase in coronary artery disease, ${ }^{11,12}$ while other studies have shown a decrease or the absence of a correlation. ${ }^{13,14}$ Some methodological difficulties, however, restrict the clinical value of these findings since most came from uncontrolled studies. These included populations with cardiovascular risk factors or atherosclerosis markers that were used without a high correlation with cardiovascular outcomes.

Cardiovascular risk assessment in SCH has been analyzed by indirect markers, such as pulse wave velocity ${ }^{15}$ and aortic distensibility. ${ }^{16}$ In terms of cardiovascular risk prediction in the general population, the most studied marker of atherosclerosis is carotid intima-media thickness. ${ }^{17-19}$ The estimated risk for every $0.1 \mathrm{~mm}$ increase in carotid intima-media thickness is a 10 to $15 \%$ increase of myocardial infarction, and a 13 to $18 \%$ increase for stroke. ${ }^{17,20,21}$

Therefore, we carried out a prospective and controlled study in participants with $\mathrm{SCH}, \mathrm{OH}$, and healthy controls (HC) to determine, as a primary endpoint, the association between $\mathrm{SCH}$ and cardiovascular risk by measuring carotid intima-media thickness.

\section{Materials and methods}

\subsection{Participants}

The study was approved by the Institutional Review Board and the Ethics Committee of our University Hospital with registration number EN18-00002. All participants provided informed consent before any study procedure.

We enrolled 54 participants: 18 with SCH (defined as a TSH $>4 \mu \mathrm{IU} / \mathrm{ml}$ and a normal free thyroxine level [0.7-1.55 ng/dl]); 18 with $\mathrm{OH}$ (defined as a TSH $>4 \mu \mathrm{IU} / \mathrm{ml}$ and a free thyroxine level $<0.7 \mathrm{ng} / \mathrm{dl}$ ); and 18 HC. The inclusion criteria were subjects 18 years of age or older with untreated $\mathrm{SCH}$, untreated $\mathrm{OH}$, and $\mathrm{HC}$ recruited from the Endocrinology Division of the University Hospital. Participants were excluded if they had a past medical history of stroke, coronary artery disease, diabetes mellitus, malignancies, systemic lupus erythematosus (SLE), rheumatoid arthritis, smoking, or the use of medications that interfere with thyroid hormone measurements or function. The elimination criteria were subjects with $\mathrm{SCH}$ who discontinued the use of levothyroxine.

\subsection{Study protocol}

In addition to determining the association between $\mathrm{SCH}$ and carotid intima-media thickness, we studied the influence of levothyroxine hormone replacement at short- and long-term follow up on carotid intima-media thickness, as a secondary endpoint. We also evaluated the correlation between the carotid intima-media thickness and age, body mass index (BMI), waist circumference, waist-hip ratio (WHR), systolic and diastolic arterial pressure (BP), level of anti-thyroid peroxidase antibodies (anti-TPO), fasting glycemia, and lipid levels.

A blood sample for a biochemical profile, thyroid hormone levels, anti-TPO, and a lipid profile was obtained in all participants. On physical examination, a particular emphasis was given to weight, height, body mass index 
(BMI), antrophometric measures, and blood pressure. Carotid assessment by ultrasound included the intimamedia thickness of the right common carotid artery (RCCA) and the left common carotid artery (LCCA). After the baseline assessment, thyroid hormone replacement was started in PH and PSH participants. In PSH participants, a carotid assessment follow-up was carried out 3 and 6 months after the baseline visit. Complete blood sampling and physical examination, as in the first visit, were repeated in this group at 3 and 6 months.

\subsection{Measurement of carotid intima-media thickness}

To perform the carotid ultrasound (ClearVue 350, L12-14 transducer), the participant was placed in a supine position with the neck extended and turned 45 degrees contralaterally to the studied side. In a longitudinal projection, the carotid intima-media was defined as the hyperechoic space between the lumen intima and the media-adventitia, the two internal and hyperechoic layers of the artery wall. The measurement was performed in the area of the carotid intima-media with the largest diameter, excluding the presence of an atherosclerotic plaque, which is defined as a carotid intima-media thickness [?]2 $\mathrm{mm} .^{21-24}$

To validate carotid intima-media thickness measurements, we selected a sample of $20 \%$ of the total studied population for evaluation by another physician. To assess intrarater reliability, the principal radiologist carried out three baseline studies in the same participant on consecutive days. For inter-rater reliability, another operator evaluated each patient in the same way. They were always blinded to clinical and imaging information.

\subsection{Statistical analysis}

Using previous literature as a basis, a significant difference of [?] $0.1 \mathrm{~mm}$ was estimated in the carotid intima-media thickness. ${ }^{17,20,21}$ With $80 \%$ power and $95 \%$ confidence, a sample size of 18 patients per group was determined, in a sample calculated for three groups. Categorical variables are reported as percentages and frequencies; continuous variables as means and standard deviations, or median and range, according to normality. Normality was determined using the Kolmogorov-Smirnov test. Categorical variables were compared using Pearson's $\chi^{2}$ test for $2 \times 2$ tables. An unpaired Student's $t$-test was used to compare continuous variables. When more than 2 groups were compared, ANOVA or the Kruskal-Wallis test were performed according to normality. All agreement analysis was made with the intraclass correlation coefficient (ICC), with 95\% confidence intervals $(95 \%$ CI). Agreement levels were classified as poor $(<0.20)$, fair $(0.21$ $0.40)$, moderate (0.41-0.60), good (0.61-0.80), and excellent (¿0.81). For correlation, a linear regression was used. A P-value [?] 0.05 was considered statistically significant. IBM SPSS version 22 (IBM, Armonk, NY, 2013) was used.

\section{Results}

\subsection{Participants}

A total of 54 participants were included (18 with SCH, 18 with $\mathrm{OH}$, and $18 \mathrm{HC}$ ). All participants completed the study. Concordance coefficients for carotid intima-media thickness were analyzed. The intraobserver intima-media thickness agreement was excellent on RCCA and LCCA (ICC 0.92 and 0.95, respectively). The interobserver intima-media thickness agreement was rated as good to excellent (ICC 0.72 on RCCA and 0.96 on LCCA).

The mean age at the beginning of the study was 35.8 years \pm 12.5 , and $74.1 \%$ of the population were women. The median TSH in the group with SCH was $6.15(4.6-34 \mu \mathrm{IU} / \mathrm{mL}), 96.4$ in the $\mathrm{OH}$ group $(10-140 \mu \mathrm{IU} / \mathrm{ml})$, and 2.6 in $\mathrm{HC}(0.9-3.9 \mu \mathrm{IU} / \mathrm{mL})(\mathrm{p}<0.001)$. The total cholesterol was greater in $\mathrm{OH} v s$. SCH and controls $(204 \pm 51.7 \mathrm{mg} / \mathrm{dL}$ in $\mathrm{OH}, 171 \pm 31.2 \mathrm{mg} / \mathrm{dL}$ in $\mathrm{SCH}$, and $186.2 \pm 24.3 \mathrm{mg} / \mathrm{dL}$ in $\mathrm{HC}, \mathrm{p}=0.041)$. The serum blood glucose was normal in all groups; however, the value was higher in the groups with hypothyroidism in comparison to the $\mathrm{HC}$ group $(94.7 \pm 7.0 \mathrm{mg} / \mathrm{dl}$ in $\mathrm{SCH}, 95.1 \pm 6.1 \mathrm{mg} / \mathrm{dL}$ in $\mathrm{OH}$, and $87.2 \pm 8.06 \mathrm{mg} / \mathrm{dL}$ in $\mathrm{HC}, \mathrm{p}=0.048)$.

In the sub-analysis between two populations, in the group with SCH vs. HC, the serum glucose level was 
statistically higher in $\mathrm{SCH}(94.7 \pm 7.0 \mathrm{mg} / \mathrm{dL}$ in $\mathrm{SCH}$ and $87.2 \pm 8.06 \mathrm{mg} / \mathrm{dL}$ in $\mathrm{HC})$. In the comparison between $\mathrm{OH}$ and $\mathrm{HC}$, the glucose level was also statistically higher in the first group $(95.1 \pm 6.1 \mathrm{mg} / \mathrm{dL}$ in $\mathrm{OH}$ and $87.2 \pm 8.06 \mathrm{mg} / \mathrm{dL}$ in $\mathrm{HC}$ ). In the comparison between $\mathrm{SCH}$ and $\mathrm{OH}$, the total cholesterol level was statistically higher in $\mathrm{OH}(171 \pm 31.2 \mathrm{mg} / \mathrm{dL}$ in $\mathrm{SCH}$ and $204 \pm 51.7 \mathrm{mg} / \mathrm{dL}$ in $\mathrm{OH})$, and also the weekly dose of levothyroxine (a median of $350.0 \mathrm{mcg}$ and $825 \mathrm{mcg}$ for $\mathrm{SCH}$ and $\mathrm{OH}$, respectively) (Table 1).

\subsection{Carotid intima-media thickness at baseline}

The carotid intima-media thickness of the RCCA and LCCA was significantly different in the $\mathrm{SCH}$ and $\mathrm{OH}$ groups when compared to HC. (RCCA [mm]: $0.486 \pm 0.106,0.512 \pm 0.124$ and $0.413 \pm 0.075$ in SCH, OH and $\mathrm{HC}$, respectively. LCCA [mm]: $0.511 \pm 0.144,0.500 \pm 0.096$ and $0.427 \pm 0.090 \mathrm{in} \mathrm{SCH}, \mathrm{OH}$ and $\mathrm{HC}$, respectively. RCCA: $\mathrm{SCH}$ vs $\mathrm{HC} \mathrm{p}=0.01$, OH vs $\mathrm{HC} \mathrm{p}=0.01$. LCCA: $\mathrm{SCH}$ vs $\mathrm{HC} \mathrm{p}=0.03$, OH vs $\mathrm{HC} \mathrm{p}=0.03)$. However, there was no significant difference in the intima-media between the groups with hypothyroidism (Table 2).

The SCH group included 13 patients with TSH $<10 \mu \mathrm{IU} / \mathrm{ml}$ and five patients with TSH $>10 \mu \mathrm{IU} / \mathrm{ml}$. There was no significant difference between the carotid intima-media thickness in relation to the TSH level (RCCA [mm]: $0.496 \pm 0.113$ and $0.440 \pm 0.022$ in TSH less and greater than $10 \mu \mathrm{IU} / \mathrm{ml}$, respectively. LCCA [mm]: $0.486 \pm 0.107$ and $0.574 \pm 0.096$ in TSH less or greater than $10 \mu \mathrm{IU} / \mathrm{ml}$, respectively).

In the linear regression analysis, a weak positive correlation was found between carotid intima-media thickness and the anti-TPO level $\left(\mathrm{p}=0.025, \mathrm{r}^{2}=0.123\right)$. No correlation was found between carotid intima-media thickness and age, BMI, waist circumference, WHR, systolic and diastolic BP, anti-TPO, fasting glycemia, and lipid panel. Even though glucose and total cholesterol showed a significant difference among groups, no correlation was found with intima-media thickness.

\subsection{Follow-up monitoring}

In terms of the median TSH level in the SCH group following treatment with levothyroxine, a significant reduction was found $(6.15 \mu \mathrm{IU} / \mathrm{mL}$ baseline, $2.5 \mu \mathrm{IU} / \mathrm{mL}$ at three months, and $2.9 \mu \mathrm{IU} / \mathrm{mL}$ at six months, $\mathrm{p}=0.005)$. When compared to baseline, three and six months follow up showed a significant decrease in the carotid intima-media thickness (RCCA [mm] $0.486 \pm 0.106,0.403 \pm 0.106$ and $0.350 \pm 0.008$ at baseline, three, and six months, respectively. LCCA [mm] $0.511 \pm 0.144,0.421 \pm 0.125$ and $0.370 \pm 0.010$ at baseline, three, and six months, respectively). Also, in the subgroup with a TSH $<10 \mu \mathrm{IU} / \mathrm{ml}$, the carotid intima-media thickness showed a significant difference after levothyroxine treatment at three and six months (RCCA [mm] $0.496 \pm 0.1060,382 \pm 0.174$ and $0.330 \pm 0.060$ at baseline, three, and six months, respectively. LCCA [mm] $0.486 \pm 0.107,0.410 \pm 0.079$ and $0.342 \pm 0.088$ at baseline, three, and six months, respectively) (Table 3). All other clinical and demographic variables studied at 3 and 6 months follow up, did not have a statistical difference.

\section{Discussion}

\subsection{Our results}

In this large prospective controlled study, we report a significant increase in the carotid intima-media thickness in adult patients with SCH when compared to healthy controls. In addition, carotid intima-media thickness showed a significant reduction following treatment with levothyroxine at a six-month follow-up. Based on these findings, the current study suggests that there is an increase in cardiovascular risk in SCH with TSH less or greater than $10 \mu \mathrm{IU} / \mathrm{ml}$, and its treatment could potentially reduce this risk.

\subsection{Comparison with previous studies}

Some population databases have shown an increased cardiovascular risk in mild SCH. In Australia, and a reanalysis of the cohort Whickham Survey in Great Britain, an increase was found in both fatal and nonfatal ischemic cardiovascular disease. ${ }^{11,22}$ In Taiwan, an increase was shown in only fatal cardiovascular disease. ${ }^{12}$ A study evaluated the correlation between mild SCH and scores on the Framingham scale for predicting cardiovascular risk. A significant positive correlation was found only in the female population. ${ }^{23}$ The limitations of the studies mentioned include the fact that due to their basis in population databases, 
these are no studies designed to evaluate the association. Another limitation is that populations with cardiovascular risk factors were included, and although the results were adjusted, possible confounders may remain.

Other studies have evaluated the association of SCH with atherosclerosis markers. Masaaki et al. evaluated the pulse wave velocity in mild SCH in comparison to controls. They found greater pulse wave velocity in mild SCH, indicating a higher degree of atherosclerosis and endothelial stiffness. One difference with our study is that the mean population age was higher $(65.2 \pm 0.57$ years $) .{ }^{9}$ Another marker for atherosclerosis that has suggested an increase in cardiovascular risk in SCH is the reduction in flow-mediated dilation. The mean of TSH was $12.5 \pm 8.6 \mu \mathrm{IU} / \mathrm{mL}$, higher than in our study. ${ }^{16}$

Unal et al. evaluated the carotid intima-media thickness in children with mild SCH (age $8.1 \pm 3.6$ years). As with our study, the intima-media thickness was greater with $\mathrm{SCH}$ in comparison with $\mathrm{HC}(0.5 \pm 0.19$ $\mathrm{mm}$ and $0.4 \pm 0.0 \mathrm{~mm}$, respectively, $\mathrm{p}=0.001)$. In children with mild $\mathrm{SCH}$, they also observed an increase in total cholesterol, LDL, total cholesterol/HDL, and LDL/HDL. A limitation of this study is that there was no regression analysis performed to confirm the significance of SCH as an independent variable in carotid intima-media thickness. ${ }^{24} \mathrm{~A}$ difference with our study is that we did not obtain a significant difference in the level of lipids in $\mathrm{SCH}$ in comparison to $\mathrm{HC}$.

A study evaluated the association of mild SCH with nonfatal ischemic cardiac disease in postmenopausal women, with no association found. The age of the population was higher than in our study, with an average of $>60$ years. ${ }^{13}$ Rhee et al. evaluated the association between mild SCH and fatal ischemic cardiac disease in populations with and without cardiac insufficiency. No association was demonstrated in the population with a history of cardiac insufficiency (population with greater cardiovascular risk). The mean age of the population was higher $\left(59.2 \pm 19.2\right.$ years) than in our study. ${ }^{14}$ Selmer et al. found a slight reduction in mortality by all causes in patients with mild SCH in a population with an average of $<60$ years. ${ }^{25}$ One of the limitations of the aforementioned studies is that they were based on population databases, without a design established to evaluate the association. Another limitation is that populations with cardiovascular risk factors were included, limiting the results of the association. ${ }^{13,14,25}$

Treatment is currently recommended in SCH with TSH $>10 \mu \mathrm{IU} / \mathrm{mL}$. Treatment in mild SCH is recommended only in populations with goiter, pregnancies, progression in TSH levels, and/or symptoms suggesting hypothyroidism with positive anti-TPO. However, the symptoms of hypothyroidism can be subjective. ${ }^{10}$

As in this, other studies have shown an improvement in the cardiovascular system following the use of levothyroxine in mild SCH. Razvi et al. found a reduction in fatal and nonfatal ischemic cardiac disease. The population age range was 40 to 70 years. However, in the subgroup with ages $>70$ years, no significant changes were observed. ${ }^{26}$ Also, the change in flow-mediated dilation with the use of levothyroxine was evaluated. An increase in this variable was obtained three months after treatment began, which suggests an improvement in endothelial function. The mean age of the population was $<60$ years, ${ }^{27}$ as was the case in our study. An improvement in cardiac contractility in a population with a mean age $<40$ years was also observed. ${ }^{28,29}$

In our study, in the three baseline groups, we obtained a weak positive correlation between carotid intimamedia thickness and the anti-TPO level. A study evaluated the anti-TPO level with the presence of atherosclerosis in cardiac catheterization. No association was found. ${ }^{30}$ Wells et al. also did not find a difference in cardiovascular risk factors in populations with or without anti-TPO. ${ }^{29}$

In terms of the carotid intima-media, thickening is considered a measurement of $>0.9 \mathrm{~mm} .{ }^{31,32}$ In our study, the mean carotid intima-media thickness was $<0.9 \mathrm{~mm}$ in the three baseline populations. Despite the foregoing, significant differences were found among the groups. In a study that evaluated the carotid intima-media thickness in subjects with $\mathrm{OH}$ and ages $<65$ years, the researchers also found a mean of $<0.9$ $\mathrm{mm} .{ }^{33}$ Selcan Koç et al. evaluated the carotid intima-media thickness in a population of 20 to 90 year-olds. Only in the group $>70$ years was thickness $>0.85 \mathrm{~mm}$. It is proposed that the cohort value for the thickening of the intima-media should be evaluated according to age. ${ }^{34}$ The reproducibility in the carotid intima-media 
measurements has been evaluated in other studies. High intraobserver and interobserver intraclass correlation coefficients have been found of 0.97 and 0.98 , respectively. ${ }^{18,35}$

\subsection{Strengths and limitations}

Our study has several limitations. First, it was not possible to reliably assess the time of $\mathrm{SCH}$ and $\mathrm{OH}$ evolution. Longer evolution of the disease could translate into more changes in the carotid intima-media; however, all baseline characteristics in the study groups were similar, and patients themselves were the control when levothyroxine was used. Also, no follow-up monitoring was provided to SCH patients to evaluate a possible decrease or increase in the TSH level without treatment. The strengths of the study include a population with no cardiovascular risk factors or established cardiovascular disease. Carotid intima-media thickness is an atherosclerosis marker that has been evaluated in the prediction of cardiovascular risk. We had no losses to follow-up, and the ultrasound measurements were very reliable.

\section{Conclusion}

There is an association between an increase in the carotid intima-media thickness in patients with SCH and $\mathrm{HC}$, even in SCH with TSH $<10 \mu \mathrm{IU} / \mathrm{mL}$; although that appears to be directly proportional to the TSH level. The increase was reversed with levothyroxine therapy at 6 months. We also found a weak positive association of carotid intima-media thickness with the anti-TPO level. Its association with important cardiovascular outcomes remains uncertain and should be studied in future studies.

\section{Conflict of interests}

The authors declare that they have no conflicts of interest.

\section{Funding}

Ultrasound equipment was provided by the Endocrinology Division of the Facultad de Medicina y Hospital Universitario "Dr. Jose E. Gonzalez" of the Universidad Autonoma de Nuevo Leon. No other funds were used.

\section{Author Contributions}

AJSG: Wrote the manuscript and performed the statistical analyses; AJSG and JGGG: Conducted the study; AJSG, GER and JGGG: Designed the original study; All authors: Involved in revising the manuscript critically.

\section{Data availability statement}

The data that support the findings of his study are available from the corresponding author upon reasonable request.

\section{References}

1. Canaris GJ, Manowitz NR, Mayor G, Ridgway EC. The Colorado thyroid disease prevalence study. Arch Intern Med. 2000;160(4):526-534.

2. Asvold BO, Vatten LJ, Bjoro T. Changes in the prevalence of hypothyroidism: the HUNT Study in Norway. Eur J Endocrinol.2013;169(5):613-620.

3. Garmendia Madariaga A, Santos Palacios S, Guillen-Grima F, Galofre JC. The incidence and prevalence of thyroid dysfunction in Europe: a meta-analysis. J Clin Endocrinol Metab. 2014;99(3):923-931.

4. Rizos CV, Elisaf MS, Liberopoulos EN. Effects of thyroid dysfunction on lipid profile. Open Cardiovasc Med J. 2011;5:76-84.

5. Ferrandino G, Kaspari RR, Spadaro O, et al. Pathogenesis of hypothyroidism-induced NAFLD is driven by intra- and extrahepatic mechanisms. Proc Natl Acad Sci U S A. 2017;114(43):E9172-E9180. 
6. Ludwig U, Holzner D, Denzer C, et al. Subclinical and clinical hypothyroidism and non-alcoholic fatty liver disease: a cross-sectional study of a random population sample aged 18 to 65 years. BMC Endocr Disord. 2015;15:41.

7. Rodriguez-Gutierrez R, Gonzalez-Velazquez C, Gonzalez-Saldivar G, Villarreal-Perez JZ, GonzalezGonzalez JG. Glucocorticoid functional reserve in full-spectrum intensity of primary hypothyroidism. Int $J$ Endocrinol. 2014;2014:313519.

8. Ning Y, Cheng YJ, Liu LJ, et al. What is the association of hypothyroidism with risks of cardiovascular events and mortality? A meta-analysis of 55 cohort studies involving 1,898,314 participants. BMC Med. $2017 ; 15(1): 21$.

9. Grais IM. Bedside skills: a 50-year personal retrospective. Tex Heart Inst J. 2010;37(6):629-632.

10. Biondi B, Cappola AR, Cooper DS. Subclinical Hypothyroidism: A Review. JAMA. 2019;322(2):153160.

11. Razvi S, Weaver JU, Vanderpump MP, Pearce SH. The incidence of ischemic heart disease and mortality in people with subclinical hypothyroidism: reanalysis of the Whickham Survey cohort. J Clin Endocrinol Metab. 2010;95(4):1734-1740.

12. Tseng FY, Lin WY, Lin CC, et al. Subclinical hypothyroidism is associated with increased risk for all-cause and cardiovascular mortality in adults. J Am Coll Cardiol. 2012;60(8):730-737.

13. LeGrys VA, Funk MJ, Lorenz CE, et al. Subclinical hypothyroidism and risk for incident myocardial infarction among postmenopausal women.J Clin Endocrinol Metab. 2013;98(6):2308-2317.

14. Rhee CM, Curhan GC, Alexander EK, Bhan I, Brunelli SM. Subclinical hypothyroidism and survival: the effects of heart failure and race.J Clin Endocrinol Metab. 2013;98(6):2326-2336.

15. Nagasaki T, Inaba M, Kumeda Y, et al. Increased pulse wave velocity in subclinical hypothyroidism. $J$ Clin Endocrinol Metab.2006;91(1):154-158.

16. Kilic ID, Tanriverdi H, Fenkci S, Akin F, Uslu S, Kaftan A. Noninvasive indicators of atherosclerosis in subclinical hypothyroidism.Indian J Endocrinol Metab. 2013;17(2):271-275.

17. Lorenz MW, Markus HS, Bots ML, Rosvall M, Sitzer M. Prediction of clinical cardiovascular events with carotid intima-media thickness: a systematic review and meta-analysis. Circulation.2007;115(4):459-467.

18. Polak JF, O'Leary DH. Carotid Intima-Media Thickness as Surrogate for and Predictor of CVD. Glob Heart. 2016;11(3):295-312 e293.

19. Rosvall M, Janzon L, Berglund G, Engstrom G, Hedblad B. Incident coronary events and case fatality in relation to common carotid intima-media thickness. J Intern Med. 2005;257(5):430-437.

20. O'Leary DH, Polak JF, Kronmal RA, Manolio TA, Burke GL, Wolfson SK, Jr. Carotid-artery intima and media thickness as a risk factor for myocardial infarction and stroke in older adults. Cardiovascular Health Study Collaborative Research Group. N Engl J Med.1999;340(1):14-22.

21. van den Oord SC, Sijbrands EJ, ten Kate GL, et al. Carotid intima-media thickness for cardiovascular risk assessment: systematic review and meta-analysis. Atherosclerosis. 2013;228(1):1-11.

22. Walsh JP, Bremner AP, Bulsara MK, et al. Subclinical thyroid dysfunction as a risk factor for cardiovascular disease. Arch Intern Med. 2005;165(21):2467-2472.

23. Lim HJ, Ahn SH, Hong S, Suh YJ. The Relationship between Subclinical Thyroid Disease and Cardiovascular Disease Risk Score in Koreans.J Korean Med Sci. 2017;32(10):1626-1632.

24. Unal E, Akin A, Yildirim R, Demir V, Yildiz I, Haspolat YK. Association of Subclinical Hypothyroidism with Dyslipidemia and Increased Carotid Intima-Media Thickness in Children. J Clin Res Pediatr 
Endocrinol. 2017;9(2):144-149.

25. Selmer C, Olesen JB, Hansen ML, et al. Subclinical and overt thyroid dysfunction and risk of all-cause mortality and cardiovascular events: a large population study. J Clin Endocrinol Metab.2014;99(7):23722382 .

26. Razvi S, Weaver JU, Butler TJ, Pearce SH. Levothyroxine treatment of subclinical hypothyroidism, fatal and nonfatal cardiovascular events, and mortality. Arch Intern Med. 2012;172(10):811-817.

27. Razvi S, Ingoe L, Keeka G, Oates C, McMillan C, Weaver JU. The beneficial effect of L-thyroxine on cardiovascular risk factors, endothelial function, and quality of life in subclinical hypothyroidism: randomized, crossover trial. J Clin Endocrinol Metab.2007;92(5):1715-1723.

28. Monzani F, Di Bello V, Caraccio N, et al. Effect of levothyroxine on cardiac function and structure in subclinical hypothyroidism: a double blind, placebo-controlled study. J Clin Endocrinol Metab.2001;86(3):11101115.

29. Wells BJ, Hueston WJ. Are thyroid peroxidase antibodies associated with cardiovascular disease risk in patients with subclinical hypothyroidism? Clin Endocrinol (Oxf). 2005;62(5):580-584.

30. Nakova VV, Krstevska B, Kostovska ES, Vaskova O, Ismail LG. The effect of levothyroxine treatment on left ventricular function in subclinical hypothyroidism. Arch Endocrinol Metab.2018;62(4):392-398.

31. Williams B, Mancia G, Spiering W, et al. 2018 ESC/ESH Guidelines for the management of arterial hypertension. Eur Heart J.2018;39(33):3021-3104.

32. Piepoli MF, Hoes AW, Agewall S, et al. 2016 European Guidelines on cardiovascular disease prevention in clinical practice: The Sixth Joint Task Force of the European Society of Cardiology and Other Societies on Cardiovascular Disease Prevention in Clinical Practice (constituted by representatives of 10 societies and by invited experts)Developed with the special contribution of the European Association for Cardiovascular Prevention \& Rehabilitation (EACPR). Eur Heart J.2016;37(29):2315-2381.

33. Nagasaki T, Inaba M, Henmi Y, et al. Decrease in carotid intima-media thickness in hypothyroid patients after normalization of thyroid function. Clin Endocrinol (Oxf). 2003;59(5):607-612.

34. Koc AS, Sumbul HE. Age should be considered in cut-off values for increased carotid intima-media thickness. Turk Kardiyol Dern Ars.2019;47(4):301-311.

35. Santos-Neto PJ, Sena-Santos EH, Meireles DP, Santos IS, Bensenor IM, Lotufo PA. Reproducibility of carotid ultrasound measurements in the Brazilian Longitudinal Study of Adult Health (ELSA-Brasil) at baseline.Braz J Med Biol Res. 2019;52(8):e8711.

Table 1. Baseline characteristics of the population.

\begin{tabular}{|c|c|c|c|c|}
\hline Characteristic & $\begin{array}{l}\text { Subclinical } \\
\text { hypothyroidism, } \\
\mathrm{n}=18\end{array}$ & $\begin{array}{l}\text { Overt } \\
\text { hypothyroidism, } \\
\mathrm{n}=18\end{array}$ & $\begin{array}{l}\text { Healthy controls, } \\
\mathrm{n}=18\end{array}$ & $\mathrm{P}$ \\
\hline $\begin{array}{l}\text { Age, years, mean } \\
\pm \mathrm{SD}\end{array}$ & $37 \pm 12.9$ & $33.9 \pm 12.1$ & $36.8 \pm 12.7$ & 0.72 \\
\hline $\begin{array}{l}\text { Gender, female, } \mathrm{n} \\
(\%)\end{array}$ & $14(63.6 \%)$ & $14(63.6 \%)$ & $15(68.2 \%)$ & 0.89 \\
\hline $\begin{array}{l}\text { TSH, } \mu \mathrm{IU} / \mathrm{ml} \text {, } \\
\text { median (range) }\end{array}$ & $6.15(4.6-34)$ & $96.4(10-140)$ & $2.6(0.9-3.9)$ & $<0.001^{*} * * * * *$ \\
\hline $\begin{array}{l}\text { Free } \mathrm{T} 4, \mathrm{ng} / \mathrm{dl}, \\
\text { median (range) }\end{array}$ & $1.01(0.78-1.53)$ & $0.33(0.09-0.5)$ & $1.15(0.89-1.40)$ & $<0.001^{*}$ \\
\hline $\begin{array}{l}\text { Anti-TPO IU } / \mathrm{ml} \text {, } \\
\text { mean } \pm \mathrm{SD}\end{array}$ & $284.27 \pm 98.0$ & $345.1 \pm 45.3$ & $135.5 \pm 30.3$ & 0.21 \\
\hline
\end{tabular}




\begin{tabular}{|c|c|c|c|c|}
\hline $\begin{array}{l}\text { Fasting serum } \\
\text { glucose, } \mathrm{mg} / \mathrm{dl} \text {, } \\
\text { mean } \pm \mathrm{SD}\end{array}$ & $94.0 \pm 7.0$ & $95.1 \pm 6.1$ & $87.2 \pm 8.06$ & $0.04 * * * * *$ \\
\hline $\begin{array}{l}\text { BUN, mg/dl, } \\
\text { mean } \pm \text { SD }\end{array}$ & $13.4 \pm 3.2$ & $12.0 \pm 4.6$ & $14.8 \pm 8.4$ & 0.38 \\
\hline $\begin{array}{l}\text { Creatinine, } \\
\mathrm{mg} / \mathrm{dl} \text {, mean } \pm \\
\mathrm{SD}\end{array}$ & $0.5 \pm 0.1$ & $0.6 \pm 0.2$ & $0.6 \pm 0.1$ & 0.41 \\
\hline $\begin{array}{l}\text { Total cholesterol, } \\
\mathrm{mg} / \mathrm{dl} \text {, mean } \pm \\
\mathrm{SD}\end{array}$ & $171 \pm 31.2$ & $204 \pm 51.7$ & $186.2 \pm 24.3$ & $0.04^{*}$ \\
\hline $\begin{array}{l}\mathrm{LDL}, \mathrm{mg} / \mathrm{dl}, \\
\text { mean } \pm \mathrm{SD}\end{array}$ & $96.7 \pm 25.3$ & $116.2 \pm 40.3$ & $107.8 \pm 27.6$ & 0.19 \\
\hline $\begin{array}{l}\mathrm{HDL}, \mathrm{mg} / \mathrm{dl} \\
\text { mean } \pm \mathrm{SD}\end{array}$ & $47.2 \pm 11.6$ & $42.5 \pm 10.5$ & $53.5 \pm 16.4$ & 0.29 \\
\hline $\begin{array}{l}\text { Triglycerides, } \\
\mathrm{mg} / \mathrm{dl}, \text { mean } \pm \\
\mathrm{SD}\end{array}$ & $117.7 \pm 42.7$ & $140.4 \pm 52.1$ & $137.5 \pm 52.2$ & 0.34 \\
\hline $\begin{array}{l}\mathrm{BMI}, \mathrm{kg} / \mathrm{m}^{2} \\
\text { mean } \pm \mathrm{SD}\end{array}$ & $26.8 \pm 4.7$ & $29.2 \pm 3.8$ & $29.6 \pm 3.6$ & 0.50 \\
\hline $\begin{array}{l}\text { Waist, cm, mean } \\
\pm \text { SD }\end{array}$ & $83.1 \pm 11.5$ & $85.6 \pm 10.1$ & $88.1 \pm 7.8$ & 0.19 \\
\hline WHI, mean $\pm \mathrm{SD}$ & $0.78 \pm 0.03$ & $0.80 \pm 0.06$ & $0.83 \pm 0.01$ & 0.14 \\
\hline $\begin{array}{l}\text { Systolic BP, } \\
\mathrm{mmHg}, \text { mean } \pm \\
\text { SD }\end{array}$ & $120.7 \pm 15.1$ & $124.3 \pm 13.3$ & $115.2 \pm 14.8$ & 0.18 \\
\hline $\begin{array}{l}\text { Diastolic BP, } \\
\text { mmHg, mean } \pm \\
\text { SD }\end{array}$ & $71.1 \pm 9.3$ & $74.1 \pm 9.6$ & $71.4 \pm 8.8$ & 0.60 \\
\hline $\begin{array}{l}\text { Weekly dose of } \\
\text { levothyroxine, } \\
\text { mcg, median } \\
\text { (range) }\end{array}$ & $350.0(250-700)$ & $825(600-1400)$ & 0 & $<0.001^{*}$ \\
\hline
\end{tabular}

Statistics in sub-analysis: ${ }^{*} \mathrm{SCH}$ versus $\mathrm{OH}$ : TSH $\mathrm{p}<0.001$, free $\mathrm{t} 4 \mathrm{p}<0.001$, total cholesterol $\mathrm{p}=0.03$, weekly dose of levothyroxine $\mathrm{p}<0.001$. ${ }^{* *} \mathrm{SCH}$ versus $\mathrm{HC}$ : TSH $\mathrm{p}=0.003$, glucose $\mathrm{p}=0.02$. ${ }^{* * *} \mathrm{OH}$ versus HC: TSH $\mathrm{p}<0.001$, T4L $\mathrm{p}<0.001$, glucose $\mathrm{p}=0.01$.

$\mathrm{TSH}=$ thyroid stimulating hormone; $\mathrm{BMI}=$ body mass index; $\mathrm{WHI}=$ waist-hip index; $\mathrm{BP}=$ blood pressure; Anti-TPO = anti-thyroid peroxidase antibodies; BUN = blood urea nitrogen; LDL $=$ low-density cholesterol; $\mathrm{HDL}=$ high-density cholesterol. $\mathrm{P}$ value was obtained with ANOVA for comparison of means with normal distribution and the Kruskal-Wallis test with non-normal distribution for three groups, and Student's $t$ for two groups. The comparison of percentages was obtained with the Chi-square test.

Table 2. Carotid intima-media thickness in three population groups.

\begin{tabular}{llll}
\hline & Subclinical hypothyroidism, $\mathrm{n}=18$ & Overt hypothyroidism, $\mathrm{n}=18$ & Healthy controls, $\mathrm{n}=18$ \\
\hline Intima-media RCCA & $0.486 \pm 0.106$ & $0.512 \pm 0.124$ & $0.413 \pm 0.075$ \\
Intima-media LCCA & $0.511 \pm 0.144$ & $0.500 \pm 0.096$ & $0.427 \pm 0.090$ \\
\hline
\end{tabular}


Data are $\mathrm{mm}$, mean $\pm \mathrm{SD}$

RCCA = Right common carotid artery; LCCA=Left common carotid artery

Carotid intima-media thickness between population groups

\begin{tabular}{ll}
\hline Group & $\mathrm{P}$ \\
\hline RCCA_SCH vs RCCA_HC & 0.01 \\
LCCA_SCH vs LCCA_HC & 0.03 \\
RCCA_OH vs RCCA_HC & 0.01 \\
LCCA_OH vs LCCA_HC & 0.03 \\
RCCA_SCH vs RCCA_OH & 0.36 \\
LCCA_SCH vs LCCA_OH & 0.61 \\
\hline
\end{tabular}

RCCA =Right common carotid artery; LCCA=Left common carotid artery; SCH=subclinical hypothyroidism; $\mathrm{OH}$, overt hypothyroidism; $\mathrm{HC}=$ Healthy control.

$\mathrm{p}$ is based on Student's $t$.

Table 3. Carotid intima-media in subclinical hypothyroidism. Before and after treatment with levothyroxine.

Baseline

Total population of subclinical hypothyroidism $(n=18)$

RCCA intima-media

Total population of subclinical hypothyroidism

LCCA intima-media

$0.486 \pm 0.106$

Subclinical hypothyroidism with $\mathrm{TSH}_{¡} 10 \mu \mathrm{UI} / \mathrm{ml}(\mathrm{n}=13)$

RCCA intima-media

$0.511 \pm 0.144$

LCCA intima-media

Subclinical hy
$0.496 \pm 0.106$

$0.486 \pm 0.107$

Data are $\mathrm{mm}$, mean $\pm \mathrm{SD}$

$\mathrm{RCCA}=$ Right common carotid artery; LCCA = Left common carotid artery.

$\mathrm{p}$ is based on Student's $t$-test. 